\title{
Two-year outcome comparison of decompression in 14 lipomatosis cases with 169 degenerative lumbar spinal stenosis cases: a Swiss prospective multicenter cohort study
}

\author{
Ulrich, Nils H ; Gravestock, Isaac ; Winklhofer, Sebastian ; Peyneshki, Iliya ; Wertli, Maria M ; \\ Pichierri, Giuseppe ; Fekete, Tamás F ; Porchet, François ; Farshad, Mazda ; Steurer, Johann ; \\ Burgstaller, Jakob M ; LSOS Study Group
}

\begin{abstract}
PURPOSE Spinal epidural lipomatosis (SEL) is defined as an abnormal and extensive accumulation of unencapsulated adipose tissue within the spinal epidural space. To date, there is a lack of high-level evidence studies reporting the outcome of surgical treatment of symptomatic SEL in patients with lumbar spinal stenosis (LSS). The aim was to compare clinical outcomes in patients with symptomatic LSS with and without SEL who underwent decompression surgery alone at the 12- and 24-month follow-up. METHODS One hundred and eighty-three patients met the inclusion criteria, of which 14 had mainly SEL on at least one level operated in addition to possible degenerative changes on other levels and 169 degenerative LSS only. The main outcomes were pain (Spinal Stenosis Measure (SSM) symptoms), disability (SSM function), and quality of life [EQ-5D-3L summary index (SI)] at 24-month follow-up, and minimal clinically important difference (MCID) in SSM symptoms, SSM function, and EQ-5D-3L SI. RESULTS The multiple regression linear models showed that SEL was associated with worse SSM symptoms $(p=0.045)$ and EQ-5D-3L SI scores $(p=0.026)$ at 24-month follow-up, but not with worse SSM function scores. Further, depression (in all models) was negatively associated with better clinical outcomes at 24-month follow-up. In the outcomes SSM symptoms and EQ-5D-3L SI, distinctly more patients in the classical LSS group reached MCID than in the SEL group $(71.3 \%$ and $62.3 \%$ vs. $50.0 \%$ and $42.9 \%$ ). CONCLUSIONS Our study demonstrated that decompression alone surgery was associated with significant improvement in disability in both groups at 2 years, but not in pain and quality of life in patients with SEL.
\end{abstract}

DOI: https://doi.org/10.1007/s00586-020-06449-w

Posted at the Zurich Open Repository and Archive, University of Zurich

ZORA URL: https://doi.org/10.5167/uzh-187831

Journal Article

Accepted Version

Originally published at:

Ulrich, Nils H; Gravestock, Isaac; Winklhofer, Sebastian; Peyneshki, Iliya; Wertli, Maria M; Pichierri, Giuseppe; Fekete, Tamás F; Porchet, François; Farshad, Mazda; Steurer, Johann; Burgstaller, Jakob M; LSOS Study Group (2020). Two-year outcome comparison of decompression in 14 lipomatosis cases with 169 degenerative lumbar spinal stenosis cases: a Swiss prospective multicenter cohort study. European Spine Journal, 29(9):2243-2253.

DOI: https://doi.org/10.1007/s00586-020-06449-w 


\title{
Two years outcome comparison of decompression in 14 lipomato- sis cases with 169 degenerative lumbar spinal stenosis cases: a swiss prospective multicenter cohort study
}

\author{
Nils H. Ulrich, ${ }^{*}$ M.D. ${ }^{1,5}$, Isaac Gravestock, ${ }^{*}$ Ph.D. ${ }^{1}$, Sebastian Winklhofer, M.D. ${ }^{2}$, Iliya Peyneshki, M.D. ${ }^{2}$, Maria \\ M. Wertli, M.D., Ph.D. ${ }^{1,3}$, Giuseppe Pichierri, Ph.D. ${ }^{1}$, Tamás F. Fekete, M.D. ${ }^{4}$, François Porchet, M.D. ${ }^{4}$, Mazda \\ Farshad, M.D., MPH5 , Johann Steurer, M.D. ${ }^{1}$, Jakob M. Burgstaller, M.D., D.M.D., Ph.D. ${ }^{1}$, on behalf of the \\ LSOS Study Group

\footnotetext{
${ }^{1}$ Horten Centre for Patient Oriented Research and Knowledge Transfer, University of Zurich, Switzerland

${ }^{2}$ Institute of Diagnostic and Interventional Radiology, University Hospital Zurich, University of Zurich, Switzerland

${ }^{3}$ Division of General Internal Medicine, Bern University Hospital, Bern University, Bern, Switzerland

${ }^{4}$ Department of Orthopedics and Neurosurgery, Spine Center, Schulthess Clinic, Zurich, Switzerland

${ }^{5}$ University Spine Centre Zurich, Balgrist University Hospital, University of Zurich, Switzerland
}

* Drs. Nils H. Ulrich and Isaac Gravestock contributed equally to this work.

Corresponding author

Nils H. Ulrich

Address for correspondence:

Nils H. Ulrich, M. D.

University Spine Centre Zurich

Balgrist University Hospital

Forchstrasse 340

8008 Zürich, Switzerland

Email: nils.ulrich@balgrist.ch

The authors have nothing to disclose. All analysis of data, manuscript preparation, and presentation is the work solely of the authors and free of commercial input, influence, or bias.

Short Title: Decompression in Lumbar spinal epidural lipomatosis 


\section{Abstract}

Purpose: Spinal epidural lipomatosis (SEL) is defined as an abnormal and extensive accumulation of unencapsulated adipose tissue within the spinal epidural space. To date, there is a lack of high-level evidence studies reporting the outcome of surgical treatment of symptomatic SEL in patients with lumbar spinal stenosis (LSS). The aim was to compare clinical outcomes in patients with symptomatic LSS with and without SEL who underwent decompression surgery alone at the 12- and 24-month follow-up.

Methods: One hundred eighty-three patients met the inclusion criteria, of which 14 had mainly SEL on at least one level operated in addition to possible degenerative changes on other levels and 169 degenerative LSS only. The main outcomes were pain (Spinal Stenosis Measure (SSM) symptoms), disability (SSM function), and quality of life (EQ-5D-3L summary index (SI)) at 24-month follow-up, and minimal clinically important difference (MCID) in SSM symptoms, SSM function, and EQ-5D-3L SI.

Results: The multiple regression linear models showed that SEL was associated with worse SSM symptoms $(p=0.045)$ and EQ-5D-3L SI scores $(p=0.026)$ at 24-month follow-up, but not with worse SSM function scores. Further, depression (in all models), was negatively associated with better clinical outcomes at 24-month follow-up. In the outcomes SSM symptoms and EQ-5D-3L SI, distinctly more patients in the classical LSS group reached MCID than in the SEL group (71.3\% and $62.3 \%$ versus $50.0 \%$ and $42.9 \%)$.

Conclusions: Our study demonstrated that decompression alone surgery was associated with significant improvement in disability in both groups at 2 years, but not in pain and quality of life in patients with SEL.

Keywords: Spinal epidural lipomatosis; Stenosis; Surgical decompression; Lumbar spine; Lipomatosis 


\section{Introduction}

Spinal epidural lipomatosis (SEL) is a rare disorder that leads to an abnormal and vast accumulation of unencapsulated fatty tissue within the spinal epidural space. Its prevalence has been reported between the unknown and 2.5\% [1]. When symptomatic, SEL can produce clinical manifestations, such as radiculopathy, back pain, or neurogenic claudication by compressing the spinal cord and/or roots [2]. The cause of SEL can be either idiopathic or secondary. The most common secondary etiology is due to exogenous long-term steroid use [3], followed by obesity [4]. Less common are endogenous steroid exposure such as Cushing's syndrome or other forms of hypercorticolism [5]. According to the literature, thoracic SEL is more frequently associated with steroid use and lumbar SEL cases are more of an idiopathic nature [6]. The most appropriate modality for evaluating fatty tissue and hence diagnosing SEL is magnetic resonance imaging (MRI) [7]. On T1-weighted images, epidural fat can be differentiated from dural content with high sensitivity [8]. A specific and typical sign of SEL is the $\mathrm{Y}$ sign as described by Kuhn presenting as a Y-shaped thecal sac compression by the excessive fat tissue not observed in other spinal pathologies [9].

There are different treatment strategies for symptomatic SEL, depending on the underlying conditions. Weight loss for obese patients [10], cessation of steroid use, or pharmaceutical pain management have been reported to be effective conservative treatment options [11]. If conservative treatment fails or patients present with abnormal or progressive neurological signs, surgical procedures offer a viable alternative [6]. To date, there is still a lack of studies with a high level evidence, reporting the outcome of surgical treatment of symptomatic SEL [12-14], except one recently published prospective study [15] concluding that "fat does not matter".

SEL may mimic other common spine conditions [16] and has been considered as a possible cause for symptomatic lumbar spinal stenosis (LSS) [17]. Therefore, the aim of our study is to compare clinical outcomes following decompression surgery for symptomatic LSS in patients 
caused either mainly by SEL on at least one level operated or by degenerative changes only (“classical LSS"). 


\section{Methods}

\section{Study design}

For this analysis, we used data from the Lumbar Stenosis Outcome Study (LSOS). The LSOS is conducted as a prospective cohort study in the Rheumatology and Spine Surgery Units at eight medical centers (which service a region in Switzerland with approximately two million inhabitants). Additional information about and inclusion criteria of LSOS is available elsewhere [18].

\section{Eligibility criteria for being included in this analysis}

All patients who met the inclusion criteria and underwent solely decompression surgery with symptomatic LSS caused either mainly by SEL on at least one operated level or by degenerative changes only ("classical" LSS), had a BMI of $\geq 25 \mathrm{~kg} / \mathrm{m}^{2}$ and were eligible on a 24-month follow-up. None of the patients had prior lumbar spine surgery.

SEL was diagnosed with the help of preoperative MRI scans. Patients were included in the SEL group if mainly unencapsulated fatty tissue within the spinal epidural space led to a compression of the dural sac on at least one operated level. Patients in the SEL group might have had stenosis on other levels caused by degenerative changes only that could have also been decompressed during the same operation if they were possible causes for the complaints.

\section{Radiological classification}

Two radiologists evaluated the baseline MRI of each patient. They categorized the grading of the SEL of each level either according to Ishikawa et al. [4] into "Grade 0" (no dorsal epidural fat $[\mathrm{EF}]$ ), "Grade 1" (EF observed within the border between the anterosuperior edges of the upper and lower neighboring neural arches, "concave"), "Grade 2" (EF observed over the border at the middle but not at the edges of neural arches on both sides, "flat"), and "Grade 3" (EF observed over the border at the edges of neural arches on at least one side, "convex or Y- 
sign") or according to Borré et al. [8] into "normal" (EF to spinal canal index $\leq 40 \%$, normal amount of EF), "grade 1" (EF to spinal canal index 41-50\%, mild overgrowth of EF), "grade 2" (EF to spinal canal index 51-74\%, moderate overgrowth of EF), and "grade 3" (EF to spinal canal index $\geq 75 \%$, severe overgrowth of $E F$ ).

Five core parameters according to the consensus paper of Andreisek et al. [19] were used to verify and to describe the severity of lumbar spinal stenosis: 1) compromise of the central zone , 2) relation between the cerebrospinal fluid and the cauda equina (Schizas classification) [20], 3) nerve root compression in the lateral recesses , 4) foraminal nerve root impingement [21], and 5) compromise of the foraminal zone. The first two refer to central stenosis, the third to lateral stenosis, and the last two to foraminal stenosis. The Meyerding classification was used to grade the severity of the spondylolisthesis [22].

\section{Surgical technique / approach}

Surgery consisted of a standard open posterior lumbar laminotomy at the affected level / levels without instrumentation. The decision to proceed with a laminotomy with a unilateral technique to decompress the fatty tissue or a midline approach with bilateral laminotomy was at the surgeons' discretion. The decision to use an operating microscope and to proceed with a single or two-level procedure was also at the surgeons' discretion. The procedures were conducted or supervised by senior neuro- or orthopedic surgeon with more than 10 years of experience after board certification.

Reoperation is defined as a renewed operation on at least one level that was operated before. In case a fusion procedure was necessary, the operation could have been extended to other levels. Reoperations that took place within three months after initial operation were not counted as reoperations. 


\section{Outcome measures}

Spinal Stenosis Measure (SSM): The SSM is a self-administered validated three-part questionnaire that was specifically designed for DLSS patients to measure the severity of symptoms and patient disability [23]. It is widely used in studies on DLSS and recommended by the North American Spine Society (NASS). It consists of three different subscales; the symptom severity subscale, the physical function subscale and the satisfaction subscale. The subscale score ranges are 1-5, 1-4 and 1-4 (best-worst). Minimal clinically important difference (MCID) in SSM symptoms is defined as an improvement (decrease) by at least 0.48 points and in SSM function improvement as by at least 0.52 points [24].

EQ-5D-3L: The EuroQol five-dimensional self-administered questionnaire (EQ-5D) is a standardized instrument to measure health-related quality of life and was developed by the EuroQol Group [25]. The first element, the EQ-5D descriptive system, measures the health state in five dimensions (mobility, self-care, usual activities, pain/discomfort, and anxiety/depression) with three levels of severity for each dimension (EQ-5D-3L). With the help of a value set (depending on population norms), the health state can be converted into a single summary index (SI) value. This value can range from -0.53 (for the French population) to 1 , with 0 representing a health state equivalent to being dead and 1 indicating full health. The French value set was used to the calculation of summary index, as there is no specific value set for Switzerland [26]. MCID is defined as an improvement (increase) by at least 0.19 points [submitted]. The second element, the EQ-5D Visual Analogue Scale (VAS), measures the health status on a vertical scale between 0 and 100 (worst to best imaginable health state) on a particular day. 


\section{Main outcomes}

The main outcomes of this study are SSM symptoms, SSM function, and EQ-5D-3L SI at 24month follow-up, and MCID in SSM symptoms, SSM function, and EQ-5D-3L SI from baseline to 24-month follow-up.

\section{Ethics}

This multi-center cohort study was conducted in compliance with all international laws and regulations as well as any applicable guidelines. Written informed consent to participate in the study has been obtained from participants. The study was approved by the independent Ethics Committee of the Canton Zurich (KEK-ZH-NR: 2010-0395/0).

\section{Statistical analysis}

Baseline: Baseline patient information is presented as means/standard deviations and counts/percentages as appropriate. Patient demographics, health information, baseline outcome scores, as well as radiological parameters are reported for the SEL and classical LSS groups. Additionally, a summary of the operations and complications is presented. Chisquared and t-test results are reported for each comparison. All analyses were conducted with R for Windows [27].

Unadjusted analysis: An initial unadjusted analysis uses t-tests to determine if there is any evidence for change from baseline to the 24-month follow-up in the three outcomes and in the two groups.

Multiple imputation: A small number of patients had missing values in some of their baseline data (depression, gonarthrosis, coxarthrosis). Ten complete datasets were generated based on multiple imputation with chained equations to be used for further analysis [28].

Adjusted analysis: To properly quantify the effect of SEL on patient outcomes, we constructed linear regression models for each of the outcomes at 24 months, which included SEL, 
the baseline outcome score, age, BMI, sex, CIRS, depression, number of levels decompressed, and epidural injection within 6 months before baseline. These factors are considered influential on outcomes of spinal surgery. The estimated model coefficients were pooled using Rubin's rules [29]. 


\section{Results}

\section{Baseline characteristics}

Figure 1 shows the patient flow of 841 patients who agreed to participate between December 2010 and December 2015. For this analysis, 183 patients met the inclusion criteria; 14 patients in the SEL group and 169 patients in the classical LSS group.

Table 1 presents the patient characteristics at baseline. Mean age was 75.4 years for the SEL group and 72.6 years for the classical LSS group. The percentage of men was $64.3 \%$ and $55.6 \%$, respectively. Only one patient in the classical LSS group was taking glucocorticoid medication and none of the patients suffered from endogenous steroid overproduction. The only statistically significant difference between the groups was in the depression subscore of $\operatorname{HADS}(\mathrm{p}=0.037)$

\section{Lipomatosis grading and morphological findings on MRI}

All patients in the SEL group demonstrated a Grade 3 in one of the two grading scores (Borré or Ishikawa classification) and at least a Grade 2 in the other grading score on at least one operated level. Of the 14 patients in the SEL group, $11(78.6 \%)$ had an isolated epidural lipomatosis (1 on L2/L3, 2 on L3/L4, and 8 on L4/L5), 2 (14.3\%) presented with a SEL at the lumbosacral junction, and 1 (7.1\%) suffered from a multisegmental SEL. Figure 2 displays representative initial MRI scans of a SEL patient (A, B) and a classical DLSS (C, D) patient.

Table 2 provides details about morphological findings on MRI. Most patients in both groups had the stenotic level (at least one moderate grading in the central or lateral core parameters) at L4/L5, followed by L3/L4 and L5/S1. Furthermore, the highest stenotic grading was severe in both groups with more than $90 \%$ and $85 \%$, respectively. Also, there were no significant differences in degenerative spondylolisthesis between the groups. 


\section{Surgical treatment, peri- and postoperative surgical complications, and reoperations}

Four $(28.6 \%)$ patients in the SEL group received a unilateral laminotomy with bilateral decompression initially, as compared with a total of 86 patients $(50.9 \%)$ in the classical LSS group. The most frequently decompressed level was L4/L5, followed by L3/L4, and in both groups, most patients underwent a two-level decompression (Table 3). The most common intraoperative complication was a dural tear in both groups (6.5\% versus $7.1 \%)$.

In the SEL group, two reoperations were performed in two patients $(14.3 \%)$. The corresponding numbers for the classical LSS group were 29 reoperations in 23 patients $(13.6 \%)$. Over $90 \%$ of the patients were reoperated due to restenosis and half of the reoperations were preceded within the first year after the initial operation (Table 3).

\section{MCID and mean changes in all outcomes at 24-month follow-up}

In the outcomes SSM symptoms and EQ-5D-3L SI, distinctly more patients in the classical LSS group reached MCID than in the SEL group (71.0\% and $62.1 \%$ versus $50.0 \%$ and $42.9 \%)$, whereas in SSM function almost as many patients improved in both groups $(65.7 \%$ versus $64.3 \%)$.

The mean changes between baseline and the 24-month follow-up in the SEL group were below the corresponding MCID values at all outcomes, whereas in the classical LSS group above the corresponding MCID values (Table 4). However, there was a distinct improvement after two years in all outcomes except for the quality of life in the SEL group. Figure 3 shows all clinical outcome measures over time with boxplots.

\section{Multiple linear regression models for all outcomes at 24-month follow-up}

The multiple linear regression models showed that SEL was associated with worse SSM symptoms $(p=0.045)$ and EQ-5D-3L SI scores $(p=0.028)$ at the 24-month follow-up, but not with worse SSM function scores. Furthermore, depression (in all models), age (in SSM 
function), BMI (in SSM function), and CIRS (in SSM symptoms) were negatively associated with better clinical outcomes at the 24-month follow-up. 


\section{Discussion}

Our analyses demonstrate that, compared to patients with classical degenerative LSS undergoing decompression alone surgery, patients with symptomatic LSS caused mainly by SEL on at least one operated level in addition to degenerative changes on other levels experienced more pain (SSM symptoms) and were more dissatisfied with their quality of life (EQ-5D-3L SI). They did not have less function (SSM function) at 24-month follow-up.

There is a lack of high level of evidence studies analyzing the effect of decompression surgery comparing patients with LSS caused by SEL versus caused by degenerative changes only. To our knowledge, there is only one prospective study by Bayerl et al. [15] who reported in their prospective study with 89 patients no difference in pain, walking distance, function, and quality of life after 3-year follow-up between patients with SEL compared to without SEL undergoing decompressive microsurgery. Our results do not fully support the findings. A possible reason for the difference in quality of life could be the lower mean age in their SEL group ( $70.0 \pm 8.3$ vs $75.4 \pm 6.9$ years in our study). On the other hand, there are a few studies with a lower level of evidence. A matched-cohort study [11] with 28 patients found weak evidence for less satisfaction after surgery in the SEL group, however, it is not clearly evident at what time point the outcome was exactly assessed what consequently hampers comparison with our results. Further, a retrospective analysis of prospectively collected data of a single center spine database with no control group reported an improvement in patient-rated outcomes scores (leg and back pain, Core Outcome Measures Index (COMI) which comprises among others back-related function and general quality of life) up to two years postoperatively [12].

In the current literature, there are a few factors discussed to be associated with SEL such as obesity, systemic corticosteroid use, and epidural corticosteroid injections $[3,6,16,30]$. In a retrospective study reviewing nearly 29'000 spine MRIs, the aforementioned factors as well as older age and male sex were found to have an association with SEL with spine-related 
symptoms in a multivariate analysis (in $35 \%$ the lipomatosis was solely located in the lumbar region, in 59\% in multiple spine regions) [1]. However, in our study, all these factors did not differ between the groups at baseline.

Lumbar spinal degenerative changes in the discs, ligamentum flavum, and facet joints are present in more than $80 \%$ of patients aged 70 years and more [31] whereas SEL is a rare disease with a prevalence rate around $6 \%$ in patients with LSS [32]. Both pathologies can lead to a narrowing of the spinal canal with or without clinical symptoms. Therefore, elderly patients with neurogenic claudication caused only by SEL and no concomitant degenerative changes is an very uncommon event as reported by Malone et al. [32], even SEL has a different origin than degenerative pathology as discussed above and in the introduction. Further, Bayerl et al. [15] showed in their study that surgical decompression in patients with SEL is an effective procedure if conservative treatment failed.

To an extent, it is still not clear why quality of life (EQ-5D-3L SI) responses turned out to be lower. It may be that other types of noncompressive spinal disease could have caused the symptoms experienced following surgery. Some subjects could have had additional changes to facet joints or discs that were not noticed on MRI scans but still inflicted pain and/or disability. These long-term degenerative changes could have caused the low level of response, particularly with the follow-up in the longer term.

Spinal fusion was an exclusion criterion in this study, as the intention was to exclusively evaluate the effects of decompression surgery. The majority of patients were treated with open bilateral decompression or unilateral decompression (using over-the-top techniques) to remove fatty tissue.

One strength of our study is that a pair of radiologists undertook the evaluation of the MRI data, which allowed for a robust evaluation of SEL. The LSOS study was originally not intended to compare LSS and SEL patients, which is a weakness of our conclusion. Furthermore, the SEL patient group was relatively small (14 patients), which limited the possibility 
to detect differences. Also the multi-center nature of our study with various but very experienced surgeons might have had an influence on our results. Further, patients in the classical LSS group had a lower extent of surgical invasiveness and less degenerative changes that could have influenced the outcomes.

\section{Conclusion}

Our study demonstrated that decompression alone surgery was associated with significant

improvement in disability in both groups at 2-year follow-up, but not in pain and quality of life in patients with SEL. 


\section{References}

1. Theyskens NC, Paulino Pereira NR, Janssen SJ, Bono CM, Schwab JH, Cha TD (2017) The prevalence of spinal epidural lipomatosis on magnetic resonance imaging. Spine $\mathrm{J}$ 17:969-976. doi: 10.1016/j.spinee.2017.02.010

2. Alvarez A, Induru R, Lagman R (2013) Considering Symptomatic Spinal Epidural Lipomatosis in the Differential Diagnosis. Am J Hosp Palliat Me 30:617-619. doi: $10.1177 / 1049909112457012$

3. Praver M, Kennedy BC, Ellis JA, D'Amico R, Mandigo CE (2015) Severity of presentation is associated with time to recovery in spinal epidural lipomatosis. J Clin Neurosci 22:12441249. doi: 10.1016/j.jocn.2015.03.005

4. Ishikawa Y, Shimada Y, Miyakoshi N, Suzuki T, Hongo M, Kasukawa Y, Okada K, Itoi E (2006) Decompression of idiopathic lumbar epidural lipomatosis: diagnostic magnetic resonance imaging evaluation and review of the literature. J Neurosurg-Spine 4:24-30. doi: DOI 10.3171/spi.2006.4.1.24

5. Bodelier AGL, Groeneveld W, van der Linden AN, Haak HR (2004) Symptomatic epidural lipomatosis in ectopic Cushing's syndrome. Eur J Endocrinol 151:765-769. doi: DOI 10.1530/eje.0.1510765

6. Al-Khawaja D, Seex K, Eslick GD (2008) Spinal epidural lipomatosis - A brief review. J Clin Neurosci 15:1323-1326. doi: 10.1016/j.jocn.2008.03.001

7. Pinkhardt EH, Sperfeld AD, Bretschneider V, Unrath A, Ludolph AC, Kassubek J (2008) Is spinal epidural lipomatosis an MRI-based diagnosis with clinical implications? A retrospective analysis. Acta Neurol Scand 117:409-414. doi: 10.1111/j.16000404.2007.00964.x

8. Borre DG, Borre GE, Aude F, Palmieri GN (2003) Lumbosacral epidural lipomatosis: MRI grading. Eur Radiol 13:1709-1721. doi: 10.1007/s00330-002-1716-4

9. Kuhn MJ, Youssef HT, Swan TL, Swenson LC (1994) Lumbar epidural lipomatosis: the "Y" sign of thecal sac compression. Comput Med Imaging Graph 18:367-372

10. Robertson SC, Traynelis VC, Follett KA, Menezes AH (1997) Idiopathic spinal epidural lipomatosis. Neurosurgery 41:68-74; discussion 74-65

11. Al-Omari AA, Phukan RD, Leonard DA, Herzog TL, Wood KB, Bono CM (2016) Idiopathic Spinal Epidural Lipomatosis in the Lumbar Spine. Orthopedics 39:163-168. doi: 10.3928/01477447-20160315-04

12. Ferlic PW, Mannion AF, Jeszenszky D, Porchet F, Fekete TF, Kleinstuck F, Haschtmann D (2016) Patient-reported outcome of surgical treatment for lumbar spinal epidural lipomatosis. Spine Journal 16:1333-1341. doi: 10.1016/j.spinee.2016.06.022

13. Gocmen S, Atabey C, Guven G, Simsek H, Colak A (2012) Management of Spinal Epidural Lipomatosis: A Report of Two Cases. J Neurol Sci-Turk 29:851-856

14. Sairyo K, Sakai T, Higashino K, Hirao B, Katoh S, Yasui N (2008) Minimally invasive excision of lumbar epidural lipomatosis using a spinal endoscope. Minim Invas Neurosur 51:43-46. doi: 10.1055/s-2007-1004569

15. Bayerl SH, Dinkelbach M, Heiden P, Prinz V, Finger T, Vajkoczy P (2019) Treatment results for lumbar epidural lipomatosis: Does fat matter? European Spine Journal 28:69-77. doi: $10.1007 / \mathrm{s} 00586-018-5771-1$

16. Fogel GR, Cunningham PY, 3rd, Esses SI (2005) Spinal epidural lipomatosis: case reports, literature review and meta-analysis. Spine J 5:202-211

17. Botwin KP, Sakalkale DP (2004) Epidural steroid injections in the treatment of symptomatic lumbar spinal stenosis associated with epidural lipomatosis. Am J Phys Med Rehabil 83:926-930 
18. Steurer J, Nydegger A, Held U, Brunner F, Hodler J, Porchet F, Min K, Mannion AF, Michel B, Collaboration LR (2010) LumbSten: The lumbar spinal stenosis outcome study. Bmc Musculoskel Dis 11. doi: Artn 254

10.1186/1471-2474-11-254

19. Andreisek G, Deyo RA, Jarvik JG, Porchet F, Winklhofer SFX, Steurer J, Grp LW (2014) Consensus conference on core radiological parameters to describe lumbar stenosis - an initiative for structured reporting. Eur Radiol 24:3224-3232. doi: DOI 10.1007/s00330-0143346-z

20. Schizas C, Theumann N, Burn A, Tansey R, Wardlaw D, Smith FW, Kulik G (2010) Qualitative grading of severity of lumbar spinal stenosis based on the morphology of the dural sac on magnetic resonance images. Spine 35:1919-1924. doi: http://dx.doi.org/10.1097/BRS.0b013e3181d359bd

21. Pfirrmann CWA, Dora C, Schmid MR, Zanetti M, Hodler J, Boos N (2004) MR Imagebased Grading of Lumbar Nerve Root Compromise due to Disk Herniation: Reliability Study with Surgical Correlation. Radiology 230:583-588. doi: 10.1148/radiol.2302021289

22. Niggemann P, Kuchta J, Grosskurth D, Beyer HK, Hoeffer J, Delank KS (2012) Spondylolysis and isthmic spondylolisthesis: impact of vertebral hypoplasia on the use of the Meyerding classification. Brit J Radiol 85:358-362. doi: 10.1259/bjr/60355971

23. Stucki G, Liang MH, Fossel AH, Katz JN (1995) Relative responsiveness of conditionspecific and generic health status measures in degenerative lumbar spinal stenosis. J Clin Epidemiol 48:1369-1378. doi: 0895-4356(95)00054-2 [pii]

24. Stucki G, Daltroy L, Liang MH, Lipson SJ, Fossel AH, Katz JN (1996) Measurement properties of a self-administered outcome measure in lumbar spinal stenosis. Spine (Phila Pa 1976) 21:796-803

25. Group TE (1990) EuroQol-a new facility for the measurement of health-related quality of life. Health policy 16:199-208

26. Matter-Walstra K, Klingbiel D, Szucs T, Pestalozzi BC, Schwenkglenks M (2014) Using the EuroQol EQ-5D in Swiss cancer patients, which value set should be applied? Pharmacoeconomics 32:591-599. doi: 10.1007/s40273-014-0151-0

27. R Core Team (2019) R: A Language and Environment for Statistical Computing. In. R Foundation for Statistical Computing, Vienna, Austria. pp. http://www.R-project.org/.

28. van Buuren S, Groothuis-Oudshoorn K (2011) mice: Multivariate Imputation by Chained Equations in R. J Stat Softw 45:1-67

29. Rubin DB (2004) Multiple imputation for nonresponse in surveys. John Wiley \& Sons

30. Kumar K, Nath RK, Nair CPV, Tchang SP (1996) Symptomatic epidural lipomatosis secondary to obesity - Case report. J Neurosurg 85:348-350. doi: DOI 10.3171/jns.1996.85.2.0348

31. Teraguchi M, Yoshimura N, Hashizume H, Muraki S, Yamada H, Minamide A, Oka H, Ishimoto Y, Nagata K, Kagotani R, Takiguchi N, Akune T, Kawaguchi H, Nakamura K, Yoshida M (2014) Prevalence and distribution of intervertebral disc degeneration over the entire spine in a population-based cohort: the Wakayama Spine Study. Osteoarthritis Cartilage 22:104-110. doi: 10.1016/j.joca.2013.10.019

32. Malone JB, Bevan PJ, Lewis TJ, Nelson AD, Blaty DE, Kahan ME (2018) Incidence of spinal epidural lipomatosis in patients with spinal stenosis. Journal of Orthopaedics 15:36-39. doi: https://doi.org/10.1016/j.jor.2017.11.001 
Table 1: Patient characteristics at baseline

\begin{tabular}{|c|c|c|c|}
\hline Variable & Classical LSS & SEL & $\mathbf{p}$ \\
\hline $\mathrm{n}$ & 169 & 14 & \\
\hline Age, years, mean (SD) & $72.64(8.34)$ & $75.36(6.91)$ & 0.237 \\
\hline Female, n $(\%)$ & $75(44.4)$ & $5(35.7)$ & 0.728 \\
\hline BMI, $\mathrm{kg} / \mathrm{m}^{2}$, mean $(\mathrm{SD})$ & $29.66(3.81)$ & $30.23(2.57)$ & 0.581 \\
\hline $\mathrm{BMI}>30, \mathrm{~kg} / \mathrm{m}^{2}, \mathrm{n}(\%)$ & $65(38.5)$ & $9(64.3)$ & 0.108 \\
\hline Current Smoker, n (\%) & $23(13.6)$ & $2(14.3)$ & 1.000 \\
\hline Civil Risk*, n (\%) & $60(35.5)$ & $4(28.6)$ & 0.817 \\
\hline Compulsory Education, n (\%) & $48(28.4)$ & $1(7.1)$ & 0.158 \\
\hline Diabetes mellitus, n (\%) & $26(15.4)$ & $2(14.3)$ & 1.000 \\
\hline Taking glucocorticoid medication, $\mathrm{n}(\%)$ & $1(0.6)$ & $0(0.0)$ & 1.000 \\
\hline Duration of symptoms $>6$ months, $n(\%)$ & $150(89.8)$ & $13(92.9)$ & 1.000 \\
\hline Back pain, n (\%) & $142(84.0)$ & $14(100.0)$ & 0.220 \\
\hline Buttocks pain, n (\%) & $135(79.9)$ & $10(71.4)$ & 0.684 \\
\hline Leg pain, $\mathrm{n}(\%)$ & $155(91.7)$ & $12(85.7)$ & 0.786 \\
\hline Coxarthrosis, $\mathrm{n}(\%)$ & $24(14.5)$ & $2(14.3)$ & 1.000 \\
\hline Gonarthrosis, $\mathrm{n}(\%)$ & $36(21.7)$ & $4(28.6)$ & 0.795 \\
\hline Problem getting better or worse in the last $3 \mathrm{mo}, \mathrm{n}(\%)$ & & & 0.419 \\
\hline Getting better & $11(6.5)$ & $0(0.0)$ & \\
\hline Staying about the same & $24(14.2)$ & $4(28.6)$ & \\
\hline Getting worse & $133(78.7)$ & $10(71.4)$ & \\
\hline Don't know & $1(0.6)$ & $0(0.0)$ & \\
\hline CIRS (mean (SD)) & $9.42(3.72)$ & $10.64(4.92)$ & 0.251 \\
\hline HADS depression, mean (SD) & $4.67(3.25)$ & $6.64(4.62)$ & 0.037 \\
\hline SSM function, mean $(\mathrm{SD})^{* 1}$ & $2.34(0.68)$ & $2.43(0.54)$ & 0.647 \\
\hline SSM symptoms, mean $(\mathrm{SD})^{* 2}$ & $3.17(0.60)$ & $3.26(0.67)$ & 0.599 \\
\hline EQ-5D-3L SI, mean (SD)*3 & $0.47(0.29)$ & $0.46(0.31)$ & 0.853 \\
\hline Epidural injection within 6 months before baseline, $\mathrm{n}(\%)$ & $47(27.8)$ & $6(42.9)$ & 0.376 \\
\hline $\begin{array}{l}\text { Duration between epidural injection and baseline, days, median } \\
\text { [IQR] }\end{array}$ & $\begin{array}{l}113.00[49.50 \\
834.50]\end{array}$ & $\begin{array}{l}134.00[46.25 \\
249.00]\end{array}$ & 0.712 \\
\hline
\end{tabular}

BMI, body mass index $\mathrm{kg} / \mathrm{m}^{2}$; HADS, Hospital Anxiety and Depression Scale (range 0-21, best-worst); CIRS, Cumulative Illness Rating Scale (range 0-56, best-worst); SI, summary index; SSM, Spinal Stenosis Measure

* Living alone, or single/divorced/widowed and living in a nursing/residential home; ${ }^{* 1}$ score range 1-4 (best-worst); ${ }^{* 2}$ score range 1-5 (best-worst); ${ }^{* 3}$ score range $-0.53-1.00$ (worst-best) 


\section{Table 2: Radiologic evaluations of the MRIs}

\begin{tabular}{|c|c|c|c|}
\hline Variable & Classical LSS & SEL & $\mathbf{p}$ \\
\hline $\mathrm{n}$ & 169 & 14 & \\
\hline \multicolumn{4}{|l|}{ Stenosis levels*, n (\%) } \\
\hline $\mathrm{L} 1 / \mathrm{L} 2$ & $52(30.8)$ & $4(28.6)$ & 1.000 \\
\hline $\mathrm{L} 2 / \mathrm{L} 3$ & $97(57.4)$ & $11(78.6)$ & 0.206 \\
\hline $\mathrm{L} 3 / \mathrm{L} 4$ & $145(85.8)$ & $11(78.6)$ & 0.733 \\
\hline L4/L5 & $161(95.3)$ & $14(100.0)$ & 0.879 \\
\hline $\mathrm{L} 5 / \mathrm{S} 1$ & $111(65.7)$ & $11(78.6)$ & 0.491 \\
\hline No. stenotic levels*, n (\%) & & & $\mathrm{NaN}$ \\
\hline 0 & $0(0.0)$ & $0(0.0)$ & \\
\hline 1 & $14(8.3)$ & $0(0.0)$ & \\
\hline 2 & $31(18.3)$ & $3(21.4)$ & \\
\hline 3 & $37(21.9)$ & $1(7.1)$ & \\
\hline 4 & $56(33.1)$ & $8(57.1)$ & \\
\hline 5 & $31(18.3)$ & $2(14.3)$ & \\
\hline Central stenosis $* 1, \mathrm{n}(\%)$ & $163(96.4)$ & $14(100.0)$ & 1.000 \\
\hline Lateral stenosis $* 2, \mathrm{n}(\%)$ & $166(98.2)$ & $13(92.9)$ & 0.712 \\
\hline Foraminal stenosis $* 3, \mathrm{n}(\%)$ & $156(92.3)$ & $14(100.0)$ & 0.592 \\
\hline Highest stenotic grading $* 4, n(\%)$ & & & $\mathrm{NaN}$ \\
\hline None & $0(0.0)$ & $0(0.0)$ & \\
\hline Mild & $1(0.6)$ & $0(0.0)$ & \\
\hline Moderate & $15(8.9)$ & $2(14.3)$ & \\
\hline Severe & $153(90.5)$ & $12(85.7)$ & \\
\hline \multicolumn{4}{|l|}{ Spondylolisthesis ${ }^{* 5}, \mathrm{n}$ levels (\%) } \\
\hline $\mathrm{L} 1 / \mathrm{L} 2$ & $8(4.7)$ & $2(14.3)$ & 0.368 \\
\hline $\mathrm{L} 2 / \mathrm{L} 3$ & $10(5.9)$ & $2(14.3)$ & 0.513 \\
\hline $\mathrm{L} 3 / \mathrm{L} 4$ & $38(22.5)$ & $2(14.3)$ & 0.706 \\
\hline L4/L5 & $61(36.1)$ & $3(21.4)$ & 0.416 \\
\hline $\mathrm{L} 5 / \mathrm{S} 1$ & $32(18.9)$ & $2(14.3)$ & 0.942 \\
\hline
\end{tabular}

* at least one moderate grading in one of the following core parameters: compromise of the central zone, relation between fluid and cauda equina (Schizas classification), and nerve root compression in the lateral recesses; ${ }^{* 1}$ at least one moderate grading in one of the following core parameters: compromise of the central zone, relation between fluid and cauda equina (Schizas classification); $*^{2}$ at least one moderate grading in the following core parameter: nerve root compression in the lateral recesses; $*^{3}$ at least one moderate grading in one of the following core parameters: foraminal nerve root impingement and compromise of the foraminal zone; ${ }^{* 4}$ highest grading in one of the three core parameters (central, lateral) on all levels, ${ }^{* 5}$ Meyerding listhesis grade $\geq 1$ 


\section{Table 3: Peri- and postoperative surgical complications and reoperations}

\begin{tabular}{|c|c|c|c|}
\hline Variable & Classical LSS & SEL & $\mathbf{p}$ \\
\hline $\mathrm{n}$ & 169 & 14 & \\
\hline \multicolumn{4}{|l|}{ Decompression level, n (\%) } \\
\hline $\mathrm{L} 1 / \mathrm{L} 2$ & $5(3.0)$ & $0(0.0)$ & 1.000 \\
\hline $\mathrm{L} 2 / \mathrm{L} 3$ & $47(27.8)$ & $4(28.6)$ & 1.000 \\
\hline $\mathrm{L} 3 / \mathrm{L} 4$ & $110(65.1)$ & $10(71.4)$ & 0.852 \\
\hline L4/L5 & $129(76.3)$ & $13(92.9)$ & 0.275 \\
\hline $\mathrm{L} 5 / \mathrm{S} 1$ & $23(13.6)$ & $4(28.6)$ & 0.261 \\
\hline Levels decompressed, n (\%) & & & 0.210 \\
\hline 1 & $64(37.9)$ & $2(14.3)$ & \\
\hline 2 & $71(42.0)$ & $8(57.1)$ & \\
\hline $3+$ & $34(20.1)$ & $4(28.6)$ & \\
\hline \multicolumn{4}{|l|}{ Complications, $\mathrm{n}(\%)$} \\
\hline Intraoperative bleeding & $4(2.4)$ & $0(0.0)$ & 1.000 \\
\hline Intraoperative dural tear & $11(6.5)$ & $1(7.1)$ & 1.000 \\
\hline Postoperative wound infection & $2(1.2)$ & $0(0.0)$ & 1.000 \\
\hline Postoperative osseous infection & $1(0.6)$ & $0(0.0)$ & 1.000 \\
\hline Postoperative other* & $16(9.5)$ & $1(7.1)$ & 1.000 \\
\hline Days between baseline and operation, median [IQR] & $11.00[3.00,30.00]$ & $38.50[24.25,66.25]$ & 0.007 \\
\hline No. of reoperations in total, $\mathrm{n}(\%)$ & 29 & 2 & \\
\hline Patients with & & & 0.774 \\
\hline 1 reoperation, $\mathrm{n}(\%)$ & $23(79.3)$ & $2(100.0)$ & \\
\hline 2 reoperations, $\mathrm{n}(\%)$ & $5(17.2)$ & $0(0.0)$ & \\
\hline 3 reoperations, $\mathrm{n}(\%)$ & $1(3.4)$ & $0(0.0)$ & \\
\hline Indication: restenosis & $26(89.7)$ & $2(100.0)$ & 1.000 \\
\hline Indication: infection & $1(3.42)$ & $0(0.0)$ & 1.000 \\
\hline Indication: epidural bleeding & $2(6.9)$ & $0(0.0)$ & 1.000 \\
\hline During the $1^{\text {st }}$ year & $16(55.2)$ & $1(50.0)$ & 1.000 \\
\hline During the $2^{\text {nd }}$ year & $9(31.0)$ & $1(50.0)$ & 1.000 \\
\hline During the $3^{\text {rd }}$ year & $4(13.8)$ & $0(0.0)$ & 1.000 \\
\hline $\begin{array}{l}\text { Median days between baseline operation and } 1^{\text {st }} \text { reoperation, } \\
\text { (IQR) }\end{array}$ & $\begin{array}{l}227.00[92.00 \\
\quad 470.00]\end{array}$ & $\begin{array}{l}354.00[329.50 \\
378.50]\end{array}$ & 0.764 \\
\hline $\begin{array}{l}\text { Median days between } 1^{\text {st }} \text { reoperation and } 2^{\text {nd }} \text { reoperation, } \\
(\mathrm{IQR})\end{array}$ & $\begin{array}{l}332.00[111.00, \\
622.00]\end{array}$ & $\mathrm{NA}[\mathrm{NA}, \mathrm{NA}]$ & NA \\
\hline $\begin{array}{l}\text { Median days between } 2^{\text {nd }} \text { reoperation and } 3^{\text {rd }} \text { reoperation, } \\
\text { (IQR) }\end{array}$ & $\begin{array}{l}420.00[420.00 \\
420.00]\end{array}$ & $\mathrm{NA}[\mathrm{NA}, \mathrm{NA}]$ & NA \\
\hline
\end{tabular}

*e.g., urosepsis, hemorrhage, wound healing deficit 
Table 4: Mean changes for all outcomes at 24-month follow-up

\begin{tabular}{lcccc}
\hline Outcome & \multicolumn{4}{c}{ Mean changes } \\
\hline & $\begin{array}{c}\text { Classical LSS, } \\
\text { mean (SE) }\end{array}$ & $\begin{array}{c}\mathrm{p} \text { - } \\
\text { value* }\end{array}$ & SEL, mean (SE) & $\begin{array}{c}\text { p- } \\
\text { value* }^{*}\end{array}$ \\
\hline $\mathrm{n}$ & 169 & & 14 & \\
SSM function & $-0.74(0.058)$ & $<0.001$ & $-0.47(0.12)$ & 0.0019 \\
SSM symptoms & $-0.96(0.066)$ & $<0.001$ & $-0.47(0.21)$ & 0.042 \\
EQ-5D-3L SI & $0.28(0.026)$ & $<0.001$ & $0.084(0.069)$ & 0.24 \\
\hline
\end{tabular}

MCID, minimal clinically important difference; SI, summary index; SSM, Spinal Stenosis Measure

* p-value for change between baseline and 24-month follow-up per group and outcome 
Figure 1: Study flow

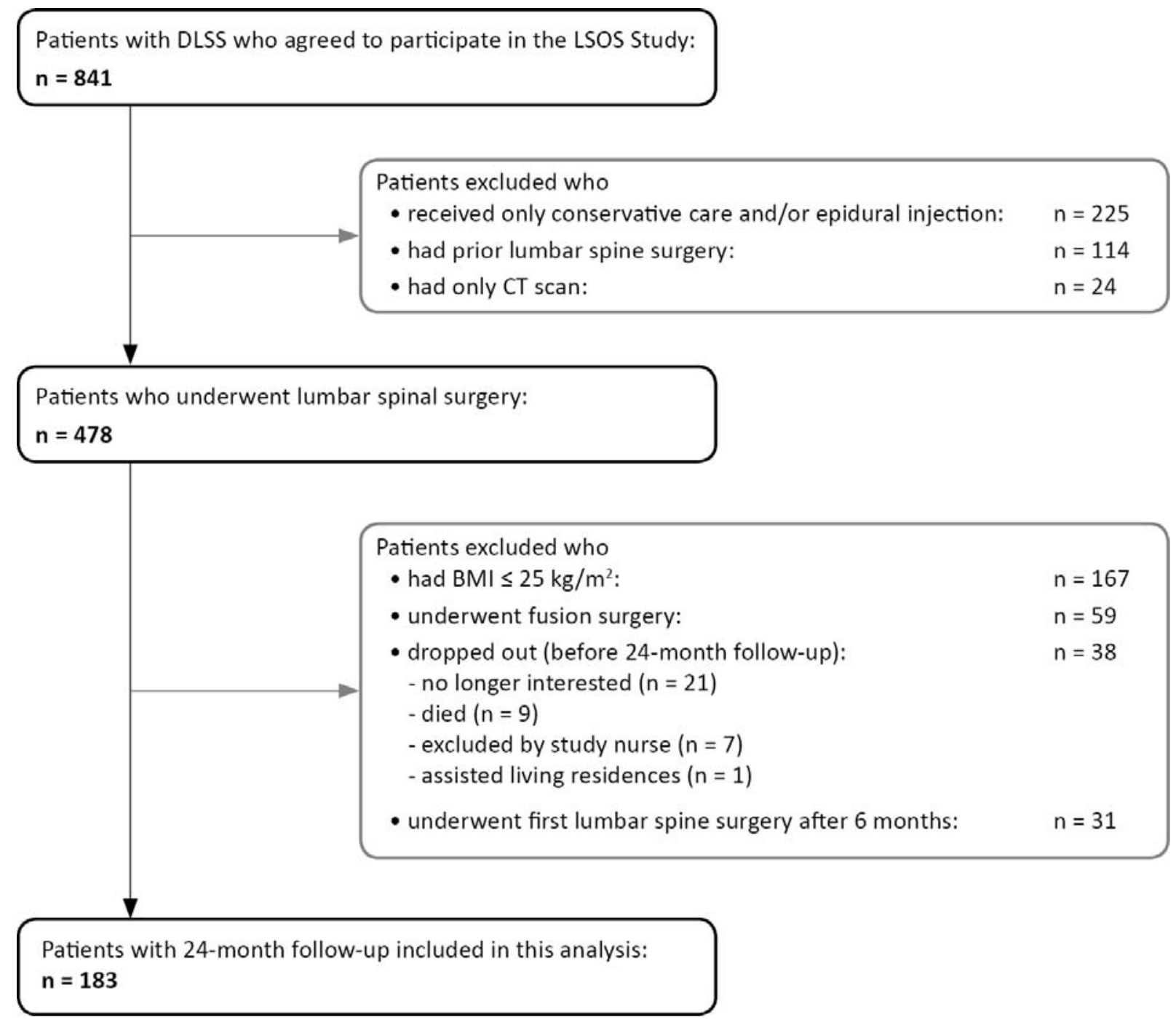


Figure 2: Representative lumbar spine MRI scans of a SEL patient (A, B) and a classical DLLS-patient (C, D).

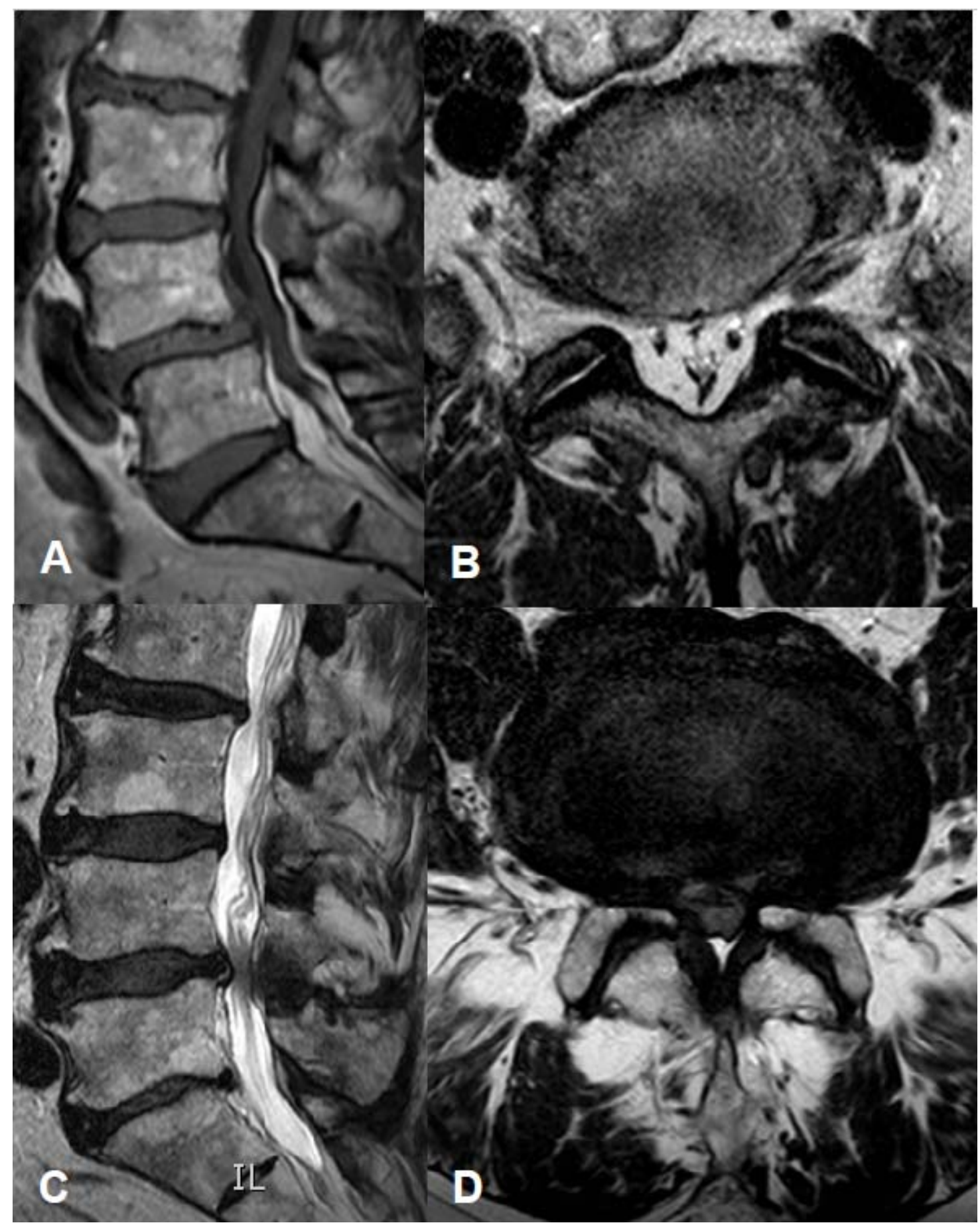

A. Sagittal T1-weighted MRI shows a monosegmental lipomatosis on level L5/S1.

B. Corresponding axial T2-weighted MRI shows the highly stenotic level on L5/S1 due to epidural lipomatosis.

C. Sagittal T2-weighted MRI shows a classical DLSS patient with a monosegmental degenerative stenosis on level L4/5.

D. T1-weighted axial image with the most stenotic level on level L4/L5 due to disc protrusion and hypertrophy of the ligamentum flavum. 
Figure 3: Course over time for all outcomes
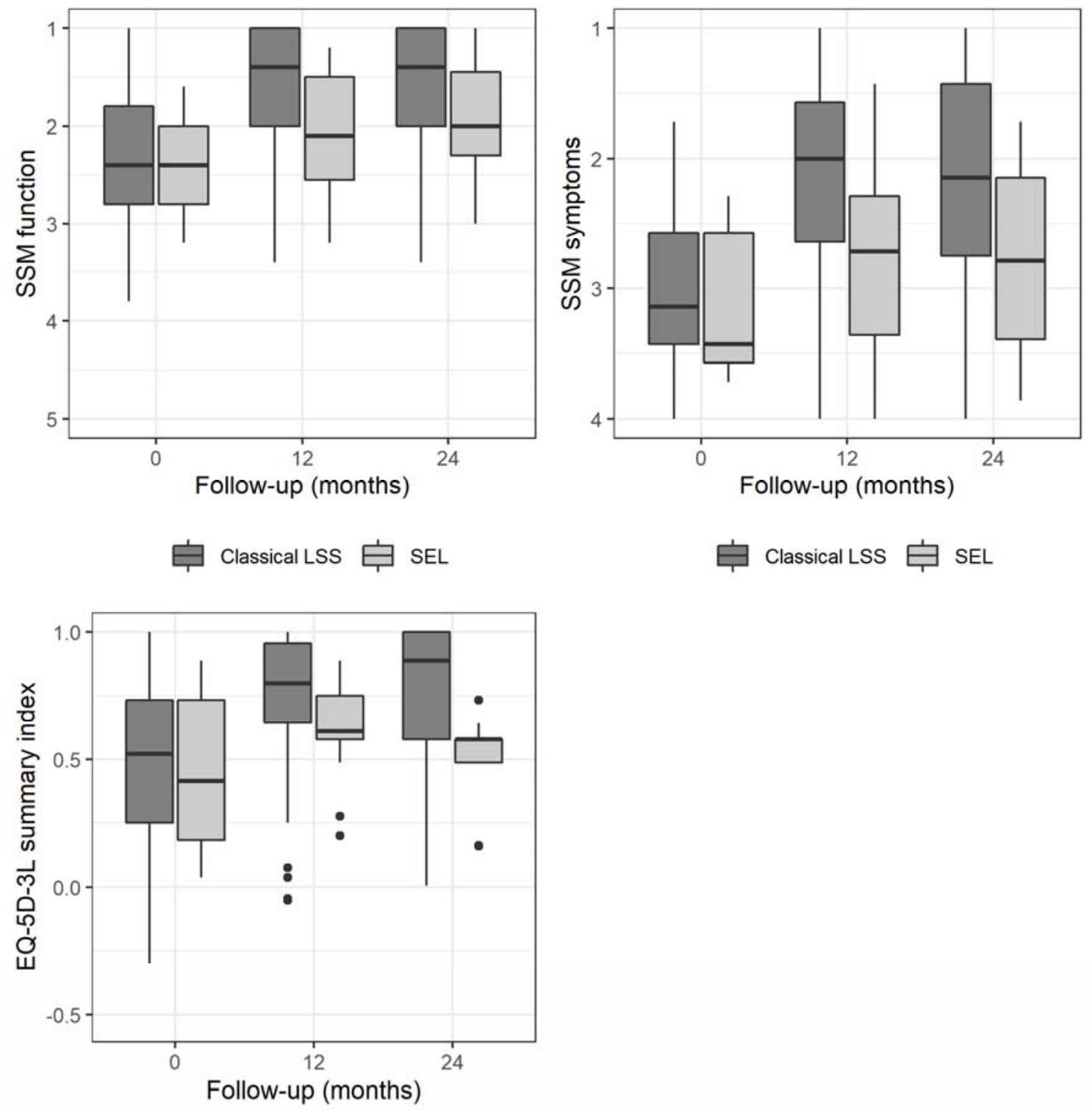

官 Classical LSS 官 SEL 
Appendix Table 1a: Multiple linear regression model for SSM function at 24-month follow-up

\begin{tabular}{lccccc}
\hline Variable & estimate & std.error & statistic & df & p.value \\
\hline (Intercept) & 1.834 & 0.120 & 15.321 & 171.017 & 0.000 \\
Age & 0.011 & 0.005 & 2.068 & 170.914 & $\mathbf{0 . 0 4 0}$ \\
BMI & 0.033 & 0.011 & 2.898 & 170.521 & $\mathbf{0 . 0 0 4}$ \\
SEL & 0.236 & 0.159 & 1.477 & 170.810 & 0.141 \\
SSM function & 0.269 & 0.066 & 4.072 & 170.663 & $\mathbf{0 . 0 0 0}$ \\
Male & -0.155 & 0.087 & -1.777 & 170.584 & 0.077 \\
Epidural injection & -0.027 & 0.092 & -0.299 & 170.696 & 0.765 \\
within 6 months be- & & & & & \\
fore baseline & 0.018 & 0.011 & 1.575 & 170.746 & 0.117 \\
CIRS & 0.034 & 0.013 & 2.531 & 164.099 & $\mathbf{0 . 0 1 2}$ \\
HADS depression & -0.067 & 0.052 & -1.289 & 170.875 & 0.199 \\
\hline Levels decompressed & & & & & \\
\hline
\end{tabular}

BMI, body mass index; CIRS, Cumulative Illness Rating Scale (range 0-56, best-worst); HADS, Hospital Anxiety and Depression Scale (range 0-21, best-worst); SSM, Spinal Stenosis Measure 
Appendix Table 1b: Multiple linear regression model for SSM symptoms at 24-month follow-up

\begin{tabular}{|c|c|c|c|c|c|}
\hline Variable & estimate & std.error & statistic & df & p.value \\
\hline (Intercept) & 2.422 & 0.163 & 14.856 & 171.017 & 0.000 \\
\hline Age & 0.008 & 0.007 & 1.077 & 170.951 & 0.283 \\
\hline BMI & 0.012 & 0.016 & 0.788 & 170.602 & 0.432 \\
\hline SEL & 0.439 & 0.217 & 2.020 & 170.832 & 0.045 \\
\hline SSM symptoms & 0.328 & 0.102 & 3.216 & 170.941 & 0.002 \\
\hline Male & -0.164 & 0.120 & -1.366 & 170.561 & 0.174 \\
\hline $\begin{array}{l}\text { Epidural injection } \\
\text { within } 6 \text { months be- } \\
\text { fore baseline }\end{array}$ & -0.047 & 0.125 & -0.379 & 170.772 & 0.705 \\
\hline CIRS & 0.031 & 0.015 & 2.045 & 170.821 & 0.042 \\
\hline HADS depression & 0.044 & 0.018 & 2.420 & 164.999 & 0.017 \\
\hline Levels decompressed & -0.053 & 0.071 & -0.753 & 170.850 & 0.453 \\
\hline
\end{tabular}

BMI, body mass index; CIRS, Cumulative Illness Rating Scale (range 0-56, best-worst); HADS, Hospital Anxiety and Depression Scale (range 0-21, best-worst); SSM, Spinal Stenosis Measure 
Appendix Table 1c: Multiple linear regression model for EQ-5D-3L SI at 24-month follow-up

\begin{tabular}{lccccc}
\hline Variable & estimate & std.error & statistic & df & p.value \\
\hline Intercept) & 0.772 & 0.049 & 15.732 & 171.017 & 0.000 \\
Age & -0.002 & 0.002 & -0.799 & 170.895 & 0.425 \\
BMI & -0.009 & 0.005 & -1.934 & 169.896 & 0.055 \\
SEL & -0.141 & 0.066 & -2.153 & 170.591 & $\mathbf{0 . 0 3 3}$ \\
EQ-5D-3L SI & 0.111 & 0.065 & 1.699 & 169.981 & 0.091 \\
Male & 0.010 & 0.036 & 0.291 & 170.183 & 0.772 \\
$\begin{array}{l}\text { Epidural injection } \\
\text { within 6 months be- }\end{array}$ & -0.027 & 0.038 & -0.709 & 170.288 & 0.479 \\
fore baseline & & & -1.887 & 170.500 & 0.061 \\
CIRS & -0.009 & 0.005 & -3.871 & 157.734 & $\mathbf{0 . 0 0 0}$ \\
HADS depression & -0.022 & 0.006 & -0.465 & 170.658 & 0.642 \\
\hline Levels decompressed & -0.010 & 0.021 & & & \\
\hline
\end{tabular}

BMI, body mass index; CIRS, Cumulative Illness Rating Scale (range 0-56, best-worst); HADS, Hospital Anxiety and Depression Scale (range 0-21, best-worst); SI, summary index 